\title{
LEADERSHIP From super-hero to super-connector, changing the leadership culture in the NHS
}

\author{
Authors: Suzie Bailey ${ }^{A}$ and Anna Burhouse ${ }^{B}$
}

The NHS Long Term Plan recently published recognises the critical role of leadership to the delivery of high-quality, sustainable healthcare and sets out an ambition for compassionate and inclusive leadership behaviours. There is good evidence that the biggest influence on organisational culture is the quality of leadership, affecting patient outcomes and staff experience. However, the current NHS staff survey paints a sobering picture of the current experience of the 1.2 million staff who work in the NHS in England. Changing culture requires leadership effort and behavioural change at every level of the system, from the clinical microsystem to the national arms-length bodies. Leaders can take positive action by regularly seeking feedback, paying attention to the leadership behaviours within their team and finding ways to ensure the team can reflect and improve their team working. This opinion article offers an introduction to compassionate and inclusive leadership in healthcare. Our intention is to provide the reader with a sense of agency to act and improve local culture for the benefits of patients and staff.

KEYWORDS: Leadership, culture, compassionate, inclusion, behaviours

The NHS Long Term Plan (LTP) states that the ability of the NHS to deliver high-quality care and transform services depends on 'great leadership' at all levels of the health and care system.'

\section{What does great leadership look like?}

There is a growing evidence base and a range of case studies in both the public and private sectors, that compassionate, inclusive leadership and the organisational deployment of quality improvement methodologies can lead to improved performance. ${ }^{2,3}$ While there is a clear moral case to address diversity and inclusion, research by McKinsey shows higher financial performance in large companies where there is a greater

Authors: A director of leadership and organisational development, The King's Fund, London, UK; ${ }^{B}$ director of quality development, RUBIS.Qi, Northumbria Healthcare NHS Foundation Trust, Newcastle upon Tyne, UK and consultant child and adolescent psychotherapist, 2gether NHS Foundation Trust, Brockworth, UK proportion of women and a more mixed ethnic and cultural composition. ${ }^{4}$

In healthcare, where the triple aim is to improve care, health and cost, West also suggests that compassionate leadership and the development of high performing teams with an improvement focus is associated with lower mortality rates. 5,6

The LTP sets out a vision for leadership that is both compassionate and diverse and suggests that while this is present in some parts of the NHS, it is 'not yet commonplace'. We think this is an overly generous assessment. The NHS Staff Survey paints a quite different picture suggesting that discrimination, bullying and harassment are routinely experienced by one in four staff from their colleagues. ${ }^{7}$ While there is no way to analyse these results to know whether this is from peers or managers, in 2018 the British Medical Association published their review of the existing evidence on workplace bullying and harassment and made several policy recommendations, one of which was to help create a 'supportive and inclusive culture' including 'compassionate leadership from the very top and ... throughout the NHS system'. The annual NHS staff survey data shows there is still a long way to go on diversity (Fig 1). ${ }^{7}$

It is also important to understand the changes that are happening in the global workforce and plan for their impact.

By 2020, a generational shift will have taken place that has implications for leadership in all employment sectors, including healthcare, as many workforces will then consist of five generations. Developing a dynamic multi-generational workforce will be critical, but will present employers and leaders with challenges. Some commentators, including Prof Ian Cummings, chief executive officer of Health Education England, have highlighted the difference in motivators for generation Z compared to previous generations, 'We also need to recognise that, as millennials coming through the professional workforce now, they actually want a different offer from their employer than perhaps - dare I say - people like myself in generations that have gone before. ${ }^{9}$ It would be a huge mistake to ignore these factors, as NHS organisations will need to adapt to meet the varying needs of the future health workforce if we are to retain them.

Only two and half years ago, 13 national organisations pledged to adopt new leadership approaches in a national framework for NHS funded care in England, Developing people - improving care, to develop a better leadership culture with more support for leaders and a stronger pipeline of leaders. ${ }^{10}$

Shifting the culture to where it needs to be will take time, along with investment and relentless commitment from leaders at every 
Fig 1. Percentage of staff saying they experienced discrimination on each basis, from those who reported personally experiencing discrimination at work in the last 12 months. Adapted with permission from NHS. NHS Staff Survey Results - 2018. London: NHS, 2018.

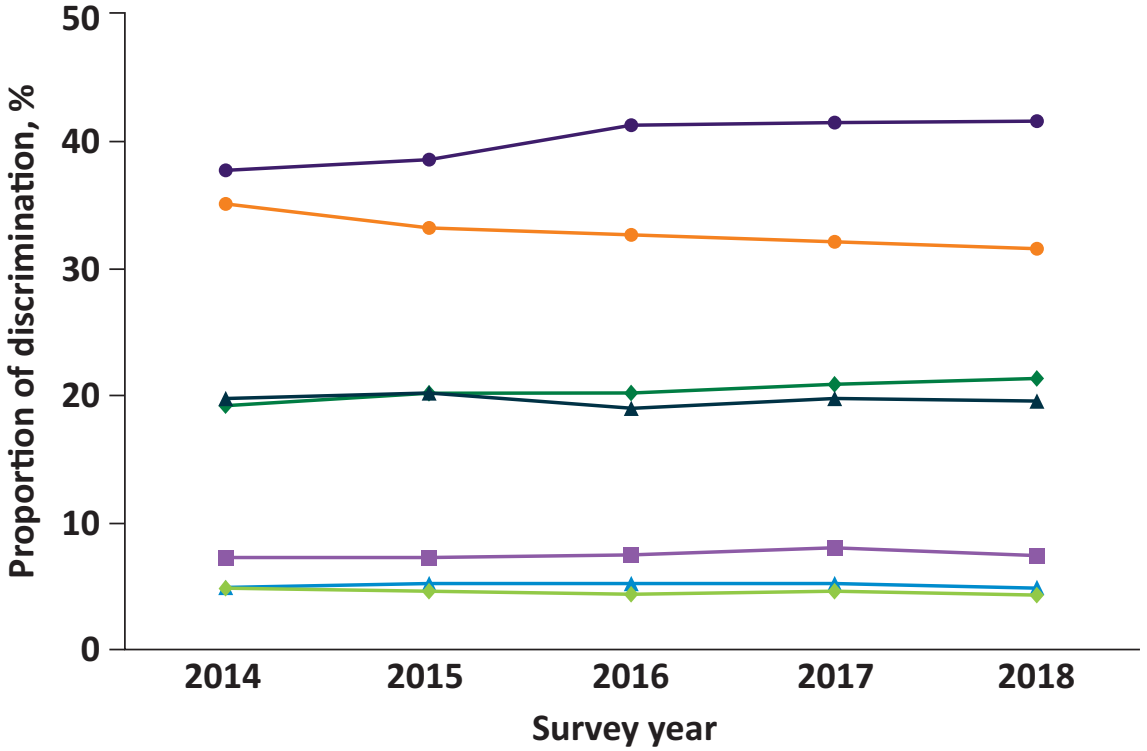

$\rightarrow$ Ethnic background
$\leftarrow$ Age
$\rightarrow-$ Sexual orientation level of the system in their everyday practice. The LTP offers some hope that there will be renewed effort to develop compassionate leadership across the NHS. However, with only a page and a half on leadership and talent management in the whole 133-page document, it is hard to know how serious the national bodies really are about this.

For medical staff, the LTP also sends some clear but perhaps controversial messages about a return to generalisation and a range of proposals on new ways of working. Recognising the extent of the workforce crisis in the NHS, the prime minister and the secretary of state for health and social care recently commissioned Baroness Dido Harding, the chair of NHS Improvement, to develop an NHS People Plan which will include the medical workforce. It will be interesting to see if the development of relational leadership skills is emphasised in this work, especially as intra-professional and cross-specialty working is highly dependent on the formation of effective working relationships.

You may find yourself frustrated with a lack of influence at the macro level of your local system, but, as a respected clinician or manager, you can have significant impact at the clinical microsystem level. It is a choice to act within your own realm of personal influence to improve care for patients and the experience of fellow staff. We urge you to experiment with becoming an anthropologist in your own system, paying attention to what is and what isn't within your control and taking positive action as a leader to improve everyday leadership.

Major failures in healthcare, including Mid Staffordshire NHS Foundation Trust, highlight quality of leadership as a pre-eminent influence factor for organisational culture. As healthcare becomes more complex we need great leaders at all levels in our health systems, especially within the 'clinical micro-systems' centred around patients.
The current regulatory system for the NHS in England formally recognises the link between good care and leadership in the well-led framework which was developed jointly between the Care Quality Commission and NHS Improvement and contains eight key lines of enquiry (KLOEs; Fig 2). ${ }^{11}$

How often do you take the time to discuss leadership and culture within your team?

Or with other teams with whom you frequently interact? How does your service measure up against the KLOEs?

The good news is that it is never too late to start paying attention to the leadership behaviours within a team and finding ways to regularly practice good teamwork. Most staff working within the NHS would identify as working within a team, perhaps many would say they are part of more than one team; but, the reality is that too few teams find regular time to develop their reflexive practice and/or are encouraged to do so by their managers.

Yet the importance of staff engagement to delivery of care was understood at the inception of the NHS. Nye Bevan gave a speech to the Institute of Hospital Administrators in April 1946, where he stated:

If we are to have a vital democracy, we can accomplish it only by the daily and hourly participation of the people who are doing the job and the people who are responsible for the administrative policies ... not only of the medical staffs of the hospitals but of the domestic staffs as well - because people seem to forget that the domestic staffs are at least as important as the rest.

The authors of this article were participants in an improvement fellowship programme that actively encouraged us to experiment with different ways of managing from our typical leadership 


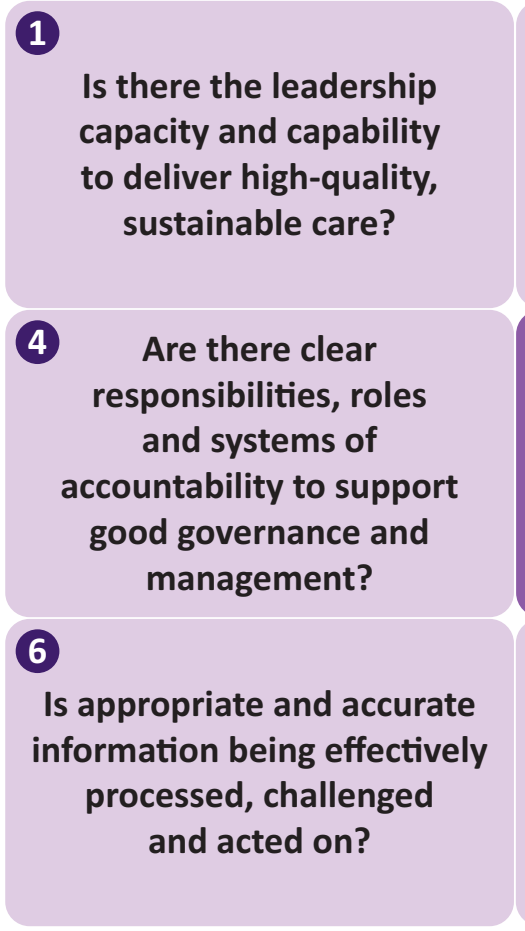

\section{2}

Is there a clear vision and credible strategy to deliver high-quality, sustainable care to people, and robust plans to deliver?

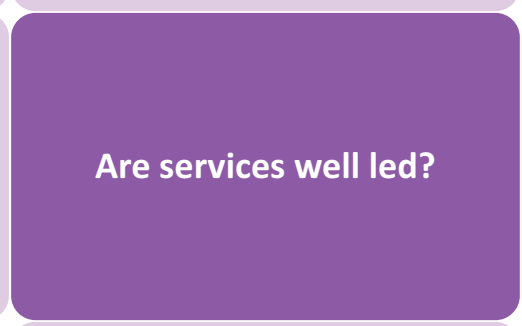

(7) Are the people who use services, the public, staff and external partners engaged and involved to support high-quality sustainable services?
(3)

$$
\begin{aligned}
& \text { Is there a culture } \\
& \text { of high-quality, } \\
& \text { sustainable care }
\end{aligned}
$$

\section{5}

$$
\begin{aligned}
& \text { Are there clear and } \\
& \text { effective processes for } \\
& \text { managing risks, issues } \\
& \text { and performance? }
\end{aligned}
$$

\section{8}

\section{Are there robust systems and processes for learning, continuous improvement and innovation?}

Fig 2. The well-led framework is structured around eight key lines of enquiry. Adapted with permission from NHS Improvement. Developmental reviews of leadership and governance using the well-led framework: guidance for NHS trusts and NHS foundation trusts. NHS Improvement; 2017.

approaches. To help you with these leadership 'tests of change', we suggest that you nurture what author Tom Rath calls 'Vital Friends' at work. ${ }^{12}$ His research included analysis of 8 million interviews conducted by Gallup and found that people who have a 'best friend at work' are seven times as likely to be engaged in their job.

If you are serious about improving your own leadership practice, here are three appreciative questions which we generated and tested in our own leadership practice, which we offer to you as an opportunity for real-time action research. Experiment by asking the questions to 10 people who work alongside you. Try to ask in an open way that indicates to people that you are genuinely interested in their thoughts and honest replies. Seek out diverse views, not only the ones who will tell you that you are great! Take time to properly reflect on their answers to provide you with potential opportunities for developing your leadership further.

> Tell me something you have seen me do recently that really helped the team and why?

$>$ What would you like me to do more and less of?

$>$ What makes you want to work with me?

These questions will hopefully act as 'openers' for conversations you probably would not, otherwise, have had with colleagues. You may find that just by signalling that you are open to learning, that you are already making a powerful leadership gesture.

If leaders and managers behave in ways that scare people, keep them 'on edge' or make them think they are under threat, the fear and stress people experience tend to trigger our most basic survival tactics, fight, flight and freeze responses. Studies from neuroscience about brain development in children show that when we are in these states our capacity to access higher order thoughts, the ones we need for the best decisions, is temporarily reduced until we feel safe again. ${ }^{13}$ Therefore, compassion is vital for leadership, because at its heart, compassion is empathy in action. It helps you to see things from the other person's point of view and understand why they acted as they did. To get the best out of people, leaders need to use empathy, compassion and emotional containment to help people feel safe, valued and to promote a culture of learning from failures.

This is particularly true when leading change. Change can trigger powerful emotions, especially grief, and if done badly, it can leave people feeling that their locus of control has been eroded or that they are being coerced into new ways of working. Fear of change can override our logical and rational reasons for wanting to improve.

Often people's resistance to change comes from:

$>$ a genuine appreciation and value of the status quo

$>$ practical restrictions, barriers and costs (perceived and real)

$>$ scepticism that the change will really be an improvement

$>$ being too busy to find the emotional space needed to consider change

$>$ the influence of peers

$>$ fear of the unknown or a reluctance to give up the habitual

$>$ a lack of trust in the innovation, the person suggesting it or both.

This can happen even when the change is relatively simple, let alone when it is complex. There is growing recognition of the importance of the psychology of change and a recent white paper from the Institute for Healthcare Improvement describes five key interrelated domains of practice, that highlights the importance of intrinsic motivation, co-design and co-production, distribution of power and the ability to adapt in action. ${ }^{14}$ How leaders handle 
the relational elements of improvement often 'make or break' the change process. Marjorie Godfrey from the Dartmouth Institute for Health Policy and Clinical Practice suggests that $20 \%$ of improvement is about deploying technical tools and skills and that $80 \%$ is relational.

This requires leaders to have a different set of skills and behaviours than have recently been valued in the NHS. Rather than 'heroic' stand-alone leaders that were expected to have all the answers, we need NHS leaders who can show us that they, too, are human, occasionally vulnerable and know about emotions. We also need leaders who can acknowledge the complexity of the task in healthcare and to know that 'no single individual has the capacity to solve problems in complex systems.'

This is because when you are far from certain about exactly what needs to be done and when there are lots of different options and opinions about how to improve, you are operating in what Ralph Stacey calls the 'zone of complexity. ${ }^{15}$ In the zone of complexity, traditional hierarchical command and control leadership styles where you are simply told what to do and not asked to think for yourself - fail.

Leadership in the zone of complexity therefore must be more facilitative and coaching in style as one of the main functions of the leader is to work with the group anxiety that facing the 'unknown' creates. Facilitated well, a leader can open opportunities for honest dialogue and co-production with the people that are most affected by the change (patients, carers and staff).

\section{What does this mean for you?}

It depends as everyone's leadership journey will be different. But we encourage you to take some practical steps towards leading and thinking about leadership in a different way. Below is a list of seven ideas. These personal leadership gestures and reflective practices can be incorporated into an ordinary working day, even if you are busy and time poor. Our encouragement would be to experiment with one of the ideas from the list below and see where it takes you and what you learn about yourself and others.

> Be more reflective about your leadership practice. Coach yourself to notice and observe more before you act, resisting the urge to reach for your super-hero cape even when everyone around you wants you to!

> Get comfortable with the idea of being 'in charge but not in control' and figure out what this means for your leadership style. $^{16}$

> Consciously try to improve how you emotionally connect and converse with others. Invest time in listening with fascination before putting your point across.

> The next time you realise you want to blame someone, stop and think about why. Ask yourself 'Who gains from the blame?'

> When you genuinely don't know an answer, say so and signal to others that you need them.

> Deliberately experiment by making a new 'leadership gesture' than your typical approach to the situation and observe the responses you get.

> Try saying 'Yes and...' instead of 'No but...' in a group conversation and watch what happens next.

Binney sums it up well, 'Accept yourself and respect people as they are; learn to see that you are not alone and not responsible in isolation. You can work out the key issues with others. ${ }^{17}$
We think this is the future of leadership and it means reimagining our idea of an effective leader, as those capable of using their emotional intelligence and relational skills alongside their technical skills. From super-hero to a super-connector, are you ready to make that change?

\section{References}

1 NHS. The NHS Long Term Plan. London: NHS, 2019. www.longtermplan. nhs.uk/publication/nhs-long-term-plan [Accessed 12 May 2019].

2 West M, Eckert R, Steward K, Pasmore B. Developing collective leadership for health care. London: The King's Fund, 2014.

3 Jones B, Woodhead T. Building the foundations for improvement: How five UK trusts built quality improvement capability at scale within their organisations. London: The Health Foundation, 2015.

4 Hunt V, Prince S, Dixon-Fyle S, Yee L. Delivering through diversity. McKinsey \& Company, 2018. www.mckinsey.com/business-functions/organization/our-insights/delivering-through-diversity.

5 Berwick DM, Nolan TW, Whittington J. The triple aim: care, health, and cost. Health Aff (Millwood) 2008;27:759-69.

6 Lyubovnikova J, West MA, Dawson JF, Carter MR. 24-Karat or fool's gold? Consequences of real team and co-acting group membership in healthcare organizations. Eur ] Work Organ Psychol 2015;24:929-50.

7 NHS. NHS Staff Survey Results - 2018. London: NHS, 2018. www.nhsstaffsurveys.com/Page/1064/Latest-Results/2018-Results [Accessed 08 May 2019].

8 British Medical Association. Bullying and harassment: how to address it and create a supportive and inclusive culture. London: BMA, 2018. www.bma.org.uk/collective-voice/policy-andresearch/education-training-and-workforce/tackling-bullyingand-harassment-in-the-nhs/bullying-and-harassment-policyrecommendations [Accessed 12 May 2019].

9 Stephenson J. NHS must cater to 'millennials' to boost nurse retention, say leaders. London: Nursing Times, 2019. www.nursingtimes. net/news/workforce/nhs-must-cater-to-millennials-to-boost-nurseretention-say-leaders/7027638.article [Accessed 10 May 2019].

10 NHS. Developing People - Improving Care. London: NHS Improvement, 2019. https://improvement.nhs.uk/resources/ developing-people-improving-care.

11 NHS Improvement. Developmental reviews of leadership and governance using the well-led framework: guidance for NHS trusts and NHS foundation trusts. London: NHS Improvement, 2017. https://improvement.nhs.uk/documents/1259/Well-led_guidance_ June_2017.pdf.

12 Rath T. Vital friends: the people you can't afford to live without. Gallup Press, 2006.

13 Shonkoff JP, Phillips DA (eds). From neurons to neighborhoods: the science of early childhood. Washington: National Academies Press, 2000.

14 Hilton K, Anderson A. IHI psychology of change framework to advance and sustain improvement. Boston: Institute for Healthcare Improvement, 2018.

15 Stacey RD. Complexity and creativity in organizations. San Francisco: Berett-Koehler, 1996.

16 Streatfield PJ. The paradox of control in organizations. London and New York: Routledge, 2001.

17 Binney G, Williams C, Wilke G. Living leadership: A practical guide for ordinary heroes. 3rd ed. London: FT Publishing International, 2012.

Address for correspondence: Suzie Bailey, The King's Fund, 11-13 Cavendish Square, London W1G OAN, UK.

Email: s.bailey@kingsfund.org.uk 